\title{
A!
}

This is an electronic reprint of the original article.

This reprint may differ from the original in pagination and typographic detail.

Niinimäki, Kirsi

Clothes Sharing in Cities: the case of fashion leasing

Published in:

The Modern Guide to the Urban Sharing Economy

DOI:

$10.4337 / 9781789909562.00027$

Published: 10/08/2021

Document Version

Publisher's PDF, also known as Version of record

Please cite the original version:

Niinimäki, K. (2021). Clothes Sharing in Cities: the case of fashion leasing. In T. Sigler, \& J. Corcoran (Eds.), The Modern Guide to the Urban Sharing Economy (pp. 254-266). (Elgar Modern Guides). Edward Elgar. https://doi.org/10.4337/9781789909562.00027

This material is protected by copyright and other intellectual property rights, and duplication or sale of all or part of any of the repository collections is not permitted, except that material may be duplicated by you for your research use or educational purposes in electronic or print form. You must obtain permission for any other use. Electronic or print copies may not be offered, whether for sale or otherwise to anyone who is not an authorised user. 


\section{Clothes sharing in cities: the case of fashion leasing}

Kirsi Niinimäki

\section{INTRODUCTION}

The fashion industry is one of the biggest global industrial sectors and uses a great deal of resources, materials, chemicals, and energy. It also deposits huge amounts of waste into soil, water and the air. In the $1990 \mathrm{~s}$, industrial manufacturing moved to lower cost countries, primarily in Asia, which has increased its environmental impacts, as in developing countries waste is not treated properly or using the latest technologies. Moreover, manufacturing in Asia causes social unsustainability through long working hours, low wages and even sweatshops in, for example, China and Bangladesh. Fast fashion leans on effective and cheap mass manufacturing, low quality and the short usage time of clothing, and this business model causes huge amounts of textile waste. For example in the UK and the USA, each consumer disposes of around $30 \mathrm{~kg}$ of textile waste annually. Consumers impulse buy, overconsume fashion, own too many garments, use them for a very short time and dispose of them frequently (Niinimäki 2018a). This has led to, for example, a $40 \%$ increase in landfilled textile waste in the USA between 1999 and 2009 (Niinimäki et al. 2020). Textile waste has increased in all Western countries. The fast fashion business model, which has been dominant for the last 25 years, has rapidly pushed material through the system, resulting in increasing amounts of textile waste and huge environmental impacts. In the fashion sector, a new understanding has emerged that much more must be done to correct these unsustainable practices. It has also become clear that a systematic approach is needed in which all stakeholders change their practices to reduce the environmental impact of this sector.

Consumers are part of this problem; their activity is essential to keep up sales figures. Consumers are needed for frequent buying, impulse buying, online buying, short usage, and the disposal of garments to keep up the fast fashion businesses based on fast-changing trends and an alluring supply of fashion (Niinimäki 2018b). Consumers do not only buy too many garments 
and dispose of them too frequently; they also own too many clothes and therefore part of their wardrobe content is 'inactive'. A study in the UK showed that as much as $30 \%$ of wardrobe contents had not been used for a year or longer, totalling an estimated value of $£ 30$ billion (WRAP 2012). To create a new, more sustainable balance in the fashion sector, we must reduce the materialistic side of consumption.

New business models have recently been sought to challenge these business practices in the fashion sector. Sustainable fashion needs many alternative approaches and a new business logic that encourages consumers to consume fashion more slowly. For example, Product-service-systems, PSS, look for new ways to fulfil consumers' needs using more sustainable fashion offerings, sometimes even without the physical product (e.g. Armstrong et al. 2015, Armstrong 2013, Niinimäki 2014). PSS provides functioning examples in the fashion and clothing field. Repair services can extend the usage time of garments by maintaining their functionality. Updating or redesigning garments can bring garments back into fashion and this way extend their fashionability, the symbolic side of fashion. Renting and leasing services can offer change and style exploration, making purchasing new garments unnecessary. In this text, the word clothing refers to everyday garments of which functionality is the core; and the word fashion has a more symbolic meaning. Fashion is linked to consumers' emotional needs for social acceptance, newness, beauty, and change.

Renting and leasing, linked to the sharing economy, present new opportunities for the fashion and clothing field and enable functionality or fashion change without the need to shop for new items. Renting and leasing have been proposed as one way to offer sustainable fashion consumption (without purchasing new items), to intensify garment use (reducing materialism) and to slow down material flows (less garments through extended usage time). In the 21st century, fashion renting and leasing have emerged as a phenomenon in the urban context. The urban context is important for fashion attributes, and as new fashion trends are emerging (Breward and Gilbert 2006). The city context can also provide new ways of consuming fashion. Therefore the sharing economy in the urban context can showcase alternatives to the current fast fashion model. The sharing economy, with its fashion wearing networks, can create fashion consumption practices and new meanings for shared fashion use, which this text will expand on. These meanings can create a new consumer mindset and offer alternatives for fashion use.

The structure of this chapter is as follows. The text starts by explaining the sharing economy and its many appearances in the fashion/clothing sector. Then the concept of leasing as a phenomen is introduced through two empirical cases from Finland that show the shift from consumers' resistance to consumers' acceptance. Using an earlier presented theory and the Finnish case, 
the section concludes by discussing the meaning of fashion leasing in an urban context. Finally the future of fashion leasing is examined.

\section{SHARING ECONOMY IN THE FASHION/CLOTHING SECTOR}

The sharing economy is not a new phenomenon, but its meaning and content has changed over time. Clothes sharing activities are, for example, lending, borrowing, donating, swapping, renting, and leasing (Table 18.1). Some activities aim to merely provide access to garments or fashion items, while others are more connected to commercial activities, either between businesses and consumers (B2C) or between consumers and other consumers $(\mathrm{C} 2 \mathrm{C})$. In a non-commercial context, sharing activities can take place within a family, for example, a child 'inherits' their big sister's or brother's clothing. Lending, borrowing and swapping can also be actions that strengthen kinships and create connections, even networks. Skill sharing can happen in, for example, mending workshops or sewing cafés. Sharing craft skills is very popular among young consumers and can be a grassroot activity or even a commercially organized action (Durrani 2019). Commerciality can also be linked to all sharing activities, but renting and leasing in particular happen in a business context. New digital platforms extend sharing opportunities and also offer consumers the possibility to take part in the fashion business and be more active in the fashion scheme. Digital platforms with services can create trust among other consumers to use these services. For example Emmy, which is a digital platform for consumers to sell brand garments to other consumers, has added services such as garment collection, garment quality checking, photographing of garments, selling of garments, and postage. These services build trust in the business and are easy for sellers and buyers to use.

New alternative strategies for sustainable fashion are emerging and it has been proposed that the sharing economy can push this change forward. As presented in the previous section, Product-Service System, PSS in particular has been proposed as one approach for different kinds of fashion offerings which could lead to more sustainable consumer practices (Niinimäki 2014). However, evidence of sustainability is still missing in many cases (for example, does the service really reduce the environmental impact of fashion consumption?).

Vigga, Rent the Runway, Lena the fashion library, and Chic by Choice are good examples of garment renting or leasing companies that have gained consumers and found their place on the clothing or fashion stage (Pike 2016). Vigga is a renting company that offers children's wear, functionality and an easy service for parents. It started in 2014 and operates online in Denmark. It makes it easy to place an online order when a child outgrows old clothing. The post brings a parcel with new garments to your home and takes away the rented 
Table 18.1 Sharing activities in the clothing sector

\begin{tabular}{lll}
\hline Activity & Motivation and aim & Who \\
\hline Lending & Access to clothing/fashion & $\begin{array}{l}\text { Between friends } \\
\text { Inside family }\end{array}$ \\
Borrowing & Access to clothing/fashion & $\begin{array}{l}\text { Between friends } \\
\text { Inside family }\end{array}$ \\
& Altruism & To charity \\
Donating & To clean out wardrope & \\
Swapping & Access clothing/fashion & Between strangers \\
& To get change in appearance & Between friends \\
Skill sharing & To learn & Between friends \\
& & Between generations \\
& Between strangers \\
Renting & Commercial & To strangers \\
Leasing & Decrease consumption & \\
& Commercial & To strangers \\
\hline
\end{tabular}

clothing items that have become too small. 'Beautiful designer wear, ethically made in organic soft cotton, with care for the environment and a fraction of new price with the new Scandinavian circular baby clothing concept, Vigga' (VIGGA - a circular subscription model for children's wear 2014). Its message to consumers is that this service does not only fulfil the functional need for new clothing but also offers an ethical choice in the children's clothing sector. This approach intensifies the use of garments; the company states in their website that in their system a baby's romper suit is not used five times or seven times, it is instead used 100, maybe 150 times (Kapfunde 2017).

'Rent the Runway' in the USA appeals more to the emotional fashion fulfilment of the consumer. It started in 2009 in New York, the USA's main fashion city. 'Rent the Runway is a subscription fashion service that allows women to rent unlimited designer styles for everyday and occasions' (Rent the Runway 2020). Its website states that women can build their own 'dream closet' by using this service, that this is the way to 'dress smarter', and that monetary limitations no longer decide the size or content of a woman's wardrobe. It even claims to offer 'peace of mind' and that 'everyone deserves a Cinderella experience' (ibid.). All these aspects appeal to the emotional side of fashion; social acceptance, the building of identity through appearance and style, and acceptance of the aesthetic look - presenting fashion as a dream or a certain kind of emotional hunt that is important to some consumers (Niinimäki 2011, 2018b). Although Rent a Runway also emphasizes the sustainability aspect in renting, the main message focuses on the fashion aspect. 'Every time you 
rent, you're saving all the water, electricity and emissions used to manufacture a new piece of clothing.... Our fashion team invests in high-quality designer pieces that last seasons, unlike fast-fashion that falls apart and ends up in landfills' (Rent the Runway 2020). Vigga and Rent the Runway are good examples of how these new kinds of models and sharing can even succeed as a business (both have been running several years).

The next section presents two examples of fashion leasing in Finland to provide an insight into this phenomenon, its initiatives and how it has established more stable ground in the consumer world.

\section{FINLAND IN THE BEGINNING: CONSUMERS' RESISTANCE}

A consumer study of product-service systems in fashion was conducted in Finland in 2013. It tested several service concepts and consumer acceptance by examining focus groups of fashion-loving female consumers (Armstrong et al. 2015). It observed that renting fashion was evaluated as being more suitable for young female consumers. The participants estimated that the 18-24-year age group was the most suitable for a renting service but that the 25-34-year age group could probably also use renting services. All kinds of fees were popular (weekly, monthly, one-time) and sustainability was seen as obviously positively correlating with fashion renting. Furthermore, renting was 'evaluated to be a test drive for new styles before investing, another way to achieve product satisfaction and avoid wrong purchases' (Armstrong et al. 2015, 37). However, an interesting issue was the consumers' hesitation to use renting services in fashion due to hygiene issues. To overcome this obstacle, trust in the service provider was essential. This was especially obvious in the response of older consumer groups (ibid.). Clothing is intimate; it lies against our bodies. Thus shared use of clothing might feel unpleasant to some consumers. The service provider had to ensure sufficient cleaning and check the condition of garments between lending times.

The obstacles to renting and leasing at that time were the meaning of materialism and fashion change.

Participants discussed their materialistic needs. Some respondents questioned whether renting services could truly substitute 'the sweetness of owning,' for example, when a garment was associated with an important memory. To other participants, a long usage time was unattractive: one participant commented 'I can't see myself wearing some garment for five years'. (Armstrong et al. 2015, 37)

It is interesting to note that even though this study is not very old, consumers have really changed their opinions regarding fashion sharing, as now we can 
see examples of fashion leasing blooming and growing in the Western world, in all main fashion capitals. The public discussion and wide media attention on the environmental impacts of the fashion industry, especially unsustainable fashion consumption practices, has increased consumers' interest in alternative consumption of offerings labelled as more sustainable. Although leasing can offer change, play, beauty experiences directly linked to the emotional side of fashion, it can also create an attractive allure and through this it can be accepted by fashion lovers, trendsetters and consumers building their identity through appearance and style but also wanting to connect themselves to the conscious consumer phenomenon.

It is obvious that alternative fashion consumption requires a greater change in consumers' mindsets in terms of everyday consumption practices. The emerging sharing economy phenomenon might provide this change. We now turn to this by exploring its emergence in Finland through two empirical cases.

\section{INITIATIVE FOR FASHION FORERUNNERS: FASHION LIBRARY IN FINLAND}

The first fashion leasing in Helsinki, the Fashion Library (Vaatelainaamo in Finnish) was established in 2011 when three friends noticed that they owned a great deal of garments, most of which remained unused in their wardrobes. They developed the idea of a shared wardrobe, to which everyone had a key and could borrow garments from at any time. 'First we just collected our own garments and invited friends to participate.' The activity expanded rapidly when it gained media attention. It became a boom, a trend; all media channels wrote about it and designers wanted to donate their design pieces to obtain publicity and promotion (Jokinen 2020). By 2015, it had around 100 participants and the garments were from local fashion designers. The leasing was based on membership, a monthly fee, and all the activities were run by volunteers and one paid employee (Pedersen and Netter 2015, 264).

The collection was based on design attributes and was curated. The idea was that participants could try out different fashion items, styles and colours and even more expensive and experimental designer pieces. 'I think it is more about the style thing, but also the sustainability is great. I think all members want to act sustainable and shop at the same time' (ibid.).

As Pedersen and Netter (2015) point out, the social aspect was new and attractive:

Helsinki Fashion Library has one big fitting room where people can try clothes together and help each other find garments that suit their needs and style: 'We have a huge fitting room where everybody fits the clothes together, so they are not 
queuing like when you go one by one, so it is a fun part of the thing that we are doing this together'. (Pedersen and Netter 2015, 266)

'The Fashion Library was fun, it supported a club and a community' (Jokinen 2020). This first fashion leasing activity in Helsinki was connected to two phenomena. One was a boom among Helsinki-based fashion designers; at this time young designers were receiving a great deal of media attention and many had started to produce their own collections and create their own design styles, which were quite unique in mainstream fashion (Chun 2018, Chun et al. 2019). The other was the rise of a new urban culture that emphasized a more active consumer, shared activities, alternative consumption, and even collaborative learning, such as the 'maker movement' (Kohtala 2016).

\section{EXTENSION THROUGH CONSUMERS' ACCEPTANCE: THE VAATEPUU CASE IN FINLAND}

In 2014, with the support of her own network, Soile-Maria Linnenmäki began the 'Vaatepuu' fashion leasing activities in her small southern hometown in Finland, Järvenpää. Before this she had been a Fashion Library customer herself in Helsinki, and thus the principles were familiar to her. Today Vaatepuu is active in five towns in Finland and is currently introducing digital services to their operations (collection online, showing garments' availability, a reservation system, a 'library card', personal borrowing history) (Linnemäki 2020). As Vaatepuu has several locations, it can circulate garment collection between towns and in this way offer change to its customers.

From the beginning, this leasing activity has had a strong social side. It has formed a local social network for participants and been strongly linked to a local urban identity. The Järvenpää city administration has supported the activity and increased Vaatepuu's visibility. Fashion leasing has formed part of the city's image-building. Linnemäki discribes the fashion leasing premises as a shared urban meeting place, a 'market square' or central place to meet like-minded people (Linnemäki 2020). Vaatepuu's interior reflects how this phenomon is part of a lifestyle; you can come in and spend some time with your friends, have a cup of coffee and a piece of raw cake, try out some new styles, and lease some garments.

The Facebook group forms a tight network, using the term 'Vaatepuu-sister', and customers who have a low customer number are proud that they have been the first and therefore 'forerunners' in the fashion leasing phenomenon (ibid.). The 'wearing network' offers not only new garments and changes in fashion experiences, but also a social network to connect with others.

Fashion leasing can educate consumers about the meaning of fashion, how it can support your self esteem, what consitutes a designer garment, garment 
quality, how to better maintain your garments, and how to avoid constant purchasing and over-consumption (Linnemäki 2020). Linnemäki herself evaluates the feeling of change as more important than fashion itself; consumers are looking to experience change through garments and fashion. She also considers the most fashionable aspect to actually be the service itself; fashion leasing is trendy (ibid.) and is connected to consumers' environmental concerns and the recent public discussion on fashion and its impact on climate change.

Most customers are between 30 and 50 years old (ibid.), perhaps the most suitable users of the physical fashion leasing service. Younger people might be more used to online purchasing and online services, and act according to impulse, easy and cheap fashion consumption, very short usage time, and premature garment disposal. The 30-50-year group may also have a more stable consumer identity (Niinimäki 2011) and want to associate themselves with the ideal of a conscious consumer.

Alternative consumption can create an urban identity and a sustainable lifestyle in general. Lifestyle refers to consumers' social practices and also the story they tell about themselves. Through their lifestyles, the reality and understanding of their own identity (who am I?) gives consumers reasons for their actions and their own consumption choices. Consumers also want to feel good through the consumption choices they make (Spaargaren and van Vliet 2000; Niinimäki 2009). The discussion on fast fashion and its environmental impact has raised the profile of a conscious consumer and even the avoidance of purchasing new items. The social aspect of fashion leasing strengthens environmental interests and therefore makes the phenomenon an even larger movement in society.

Taking part in fashion leasing can even help avoid fashion purchasing. As Linnemäki (2020) says, 'Many customers say this, and I have even experienced it myself too; When fashion sales start after Christmas, it's very hard to stay away from fashion shops and avoid purchasing new garments. Fashion leasing can really ease this pressure as well as purchasing anxiety.' In this way, fashion leasing can provide satisfaction, newness and change experiences in a more sustainable manner.

\section{THE MEANING OF FASHION LEASING IN AN URBAN CONTEXT}

Fashion leasing emerged at the same time as a new active urban culture in the Global North at the beginning of the 21st century. The maker movement has recently arisen in many Western cities, strengthening the sharing economy and consumers' more active roles. Through their actions, consumers can create new meaning for their everyday lives; they can create well-being on the individual, community and even societal level (Niinimäki 2013, 22). Participation 
can create a new kind of 'happiness' of knowing that one's actions not only support sustainable consumption but that they can also create a new kind of connection with one's own neighbourhood or community. As Linnemäki states; new urban and local subgroups are forming through leasing activitites based on friendship or profession (Linnemäki 2020). 'This feeling of connectedness builds well-being in the community, solidarity and empathy towards others' (Niinimäki 2013, 23). Consumers feel that they belong to a community and even build new friendships with like-minded others. In the fashion leasing case, their actions have an effect on the future - or at least consumers want to believe this.

Manzini and Mugendi (2016) point out that sustainability knowledge is developed through belonging to a community and is shared at the local level on a small scale:

On the one hand, [small scale] permits the participating actors to understand and manage complex socio-technical systems (in an open and democratic way). On the other hand, it enables individuals to carry out their activities, to fulfil their needs and to build their desirable futures from within organizations where human relationships remain lively and personal. (Manzini and Mugendi 2016, 279)

Fashion leasing establishes a living wearing network that can share sustainability knowledge locally. This local phenomenon can grow through social media, showing alternative fashion uses and encouraging consumers to act differently. It can also guide our attention towards the fashion system and the problems of fast fashion business models, while simultaneously teaching us slower consumption practices. These are important elements in fashion leasing. They build new wearing networks, activate the consumer's role, and through this create connection and happiness in an urban context.

\section{THE FUTURE OF FASHION LEASING}

The emergence of fashion leasing in different locations shows that sharing and leasing are accepted consumer actions in the Global North, especially among conscious consumers. As the acceptance of new ways of consuming fashion needs a certain level of wealth and environmental knowledge to gain larger social acceptance (Niinimäki 2011), fashion leasing might remain a niche local phenomenon in the north and in fashion capitals. The service aspect in fashion leasing is a trendy and urban fashion phenomenon, meaning it might also be temporary. In the sustainable development context the current fashion system should be challenged and consumers' everyday practices need to change, to rebuild our everyday practices and consumption habits to 'remake' the world. Therefore working with consumers' day-to-day reality is important 
Table 18.2 Benefits of fashion sharing

\begin{tabular}{ll}
\hline Benefits of fashion sharing & Results \\
\hline Reduction of shopping space & $\begin{array}{l}\text { Change in urban atmosphere } \\
\text { Consumption focus moves away from impulse, } \\
\text { cheap and easy fashion shopping } \\
\text { Shange in consumption }\end{array}$ \\
& $\begin{array}{l}\text { Extended usage time of garments } \\
\text { Less material waste }\end{array}$ \\
The fashion system & Decrease in environmental impacts \\
New urban culture & More powerful consumers \\
& More active citizens \\
& Wearing networks \\
\hline
\end{tabular}

in the sustainability context, and this new mindset is also important in environmental politics (Loftus 2012). The focus has to be on consumers' reality in consumption while making sustainable changes. We need to gain a deeper understanding of what fashion means to consumers. One important aspect is how consumers could have more power in the fashion system and how they could be more active on the fashion scene.

Loftus (2012) argues that as humans we are tied to social and natural relations. The sharing economy can provide social activities and a more powerful role for us as fashion consumers. These activities can support a positive urban culture, but they can also offer new sustainability knowledge on how to invite consumers to the change process taking place in fashion. Further, Schlosberg and Coles (2016) point out that these new urban phenomena in material flows can show alternative visions and even highlight new everyday practices, which could even challenge the power issues in the fashion system while transforming consumption towards sustainability. Bringing the power back to consumers shakes the position of global mega-sized fashion brands. The benefits of fashion sharing through leasing are presented in Table 18.2.

This text has focused on fashion leasing services that have a physical space that consumers can visit, try on fashion garments, meet each other, create friendships and networks, and share experiences and knowledge. As these services are moving online, this may create new challenges from the sustainability point of view. Online services increase the environmental impact through logistics and fail to provide all the facets of satisfaction (social, local and shared experience). This might result in these services not offering the same kind of emotional fullfilment and not substituting fashion purchasing; in fact it might even increase fashion consumption. From the sustainability viewpoint, a concrete physical service and an urban location can provide fashion fullfilment for consumers who are looking for change through fashion experience. The example of Vaatepuu - five towns and circulating collections - intensifies 
the potential change offered by fashion leasing. Garment leasing through online services in turn is suitable if functionality is the key need of consumers (as in the case of Vigga and leasing childrens' wear).

The future shows two possible paths for fashion sharing. On the first, consumers take a more active role in the fashion system, environmental discussion increases and alternative ways of consuming fashion begin to be more common, fashion leasing being one of these. The other option is that fashion leasing becomes an ephemeral trend and remains a very local niche phenomenon, soon to be forgotten. I would like to believe that fashion leasing, its growth, and consumers' readiness to accept new ways of consuming fashion are important steps forward. Fashion leasing is currently gaining popularity in many fashion capitals, leading us towards a better fashion future and alternative ways of fashion consumption. The locality of fashion leasing with a physical space can enhance a positive urban culture, consumer activity, connectedness, and happiness. However, moving towards online services alone might have the opposite effect.

Although fast fashion companies have recently been critiziced heavily for their huge environmental impact and unsustainability business model (e.g. Niinimäki et al. 2020), they too can find new, more sustainable business practices in the sharing economy. Some manufacturing companies are already experimenting with rental services and this approach offers opportunities to slow down the materialistic side of the fashion business. I can conclude that the sharing economy can really point the way towards a more sustainable fashion future from the consumer as well from the business perspective.

\section{ACKNOWLEDGEMENTS}

This research was supported by the Academy of Finland's Strategic Research Council's Grant no 327299 Sustainable textile systems: Co-creating resource-wise business for Finland in global textile networks / FINIX consortium.

\section{REFERENCES}

Armstrong, Cosette. 2013. "Product-Service Systems Design Thinking for Sustainable Fashion." In Sustainable Fashion: New Approaches, edited by Kirsi Niinimäki, pp. 102-109. Helsinki: Aalto ARTS Books. https://aaltodoc.aalto.fi/handle/ $123456789 / 36608$

Armstrong, Cosette, Niinimäki, Kirsi, Kujala, Sari, Karell, Essi and Chunmin Lang. 2015. "Sustainable Product-Service Systems for Clothing: Exploring Consumer Perceptions of Consumption Alternatives in Finland." Journal of Cleaner Production 97: 30-39. 
Breward, Christopher and David Gilbert. 2006. Fashion's World Cities. Oxford New York: Berg.

Chun, Namkyu. 2018. Re(dis)covering Fashion Designers; Interweaving Dressmaking to Placemaking. Doctoral dissertation, Helsinki: Aalto University. https://aaltodoc .aalto.fi/handle/123456789/34874

Chun, Namkyu, Gurova, Olga and Kirsi Niinimäki. 2019. "Fashion Dreams or Fashion Business. Helsinki as an Emerging Fashion Scene." Fashion Theory, Russian version / special issue of Nordic fashion, 55: 238-258.

Durrani, Marium. 2019. Through the Threaded Needle: A Multi-Sited Ethnography on the Sociomateriality of Garment Mending Practices. Doctoral dissertation, Helsinki: Aalto University. https://aaltodoc.aalto.fi/handle/123456789/41489

Kohtala, Cindy. 2016. Making Sustainability: How Fab Labs Address Environmental Issues. Doctoral dissertation, Helsinki: Aalto University. https://aaltodoc.aalto.fi/ handle/123456789/21755

Loftus, Alex. 2012. Everyday Environmentalism: Creating an Urban Political Ecology. Minneapolis. MN: University of Minnesota Press.

Manzini, Ezio, and Mugendi K. M'Rithaa. 2016 "Distributed Systems and Cosmopolitan Localism: An Emerging Design Scenario for Resilient Societies." Sustainable Development 24, no. 5: 275-280.

Niinimäki, Kirsi. 2009. "Consumer Values and Eco-Fashion in the Future.” In Future of the Consumer Society, Proceedings of the Conference "Future of the Consumer Society", 28-29 May, 2009, Tampere, Finland, edited by M. Koskela, and M. Vinnari, pp. 125-134. Turku: Finland Futures Research Centre, Turku School of Ecnomics.

Niinimäki, Kirsi. 2011. From Disposable to Sustainable. The Complex Interplay between Design and Consumption of Textiles and Clothing. Doctoral dissertation. Helsinki: Aalto University. https://aaltodoc.aalto.fi/handle/123456789/13770

Niinimäki, Kirsi. 2013. "Dialogue and Participation in a Good Neighborhood." In Dialogues for Sustainable Design and Art Pegadogy, the AH-Design Project, edited by Kirsi Niinimäki and Mira Kallio-Tavin, pp. 20-27. Helsinki: Aalto University. https://aaltodoc.aalto.fi/handle/123456789/13768

Niinimäki, Kirsi. 2014. "Sustainable Consumer Satisfaction in the Context of Clothing." In Product-Service System Design for Sustainability, edited by Vezzoli, Carlo, Kohtala, Cindy, Srinivasan, Amrit, Diehl, Jan, C, Fusakul, Sompit, Moi, Xin, Liu, Sateesh, Deepta, pp. 218-237. Sheffield, UK: Greenleaf.

Niinimäki, Kirsi. 2018a. Sustainable Fashion in a Circular Economy. Helsinki: Aalto ARTS Books. https://aaltodoc.aalto.fi/handle/123456789/36608

Niinimäki, Kirsi. 2018b. "Knowing Better, but Behaving Emotionally: Strong Emotional Undertones in Fast Fashion Consumption." In Eco Friendly and Fair. Fast Fashion and Consumer Behavior, edited by Carolin Becker-Leifhold and Mark Heuer, pp. 49-57. London, UK: Routledge, Taylor \& Francis.

Niinimäki, Kirsi, Peters, Greg, Dahlbo, Helena, Perry, Patsy, Rissanen, Timo and Gwilt, Alison. 2020. "The Environmental Price of Fast Fashion." Nature Reviews. Earth and Environment 1, 189-200.

Pedersen, Esben and Netter, Sarah. 2015. "Collaborative Consumption: Business Model Opportunities and Barriers for Fashion Libraries." Fashion Marketing and Management, 19, no. 3, 258-273.

Pike, Helene. 2016. "Will the Sharing Economy Work for Fashion?" Business of fashion, 8 May (online) https://www.businessoffashion.com/articles/fashion-tech/ will-the-sharing-economy-work-for-fashion-rent-the-runway-rental 
Schlosberg, David, and Coles, Romand. 2016. "The New Environmentalism of Everyday Life: Sustainability, Material Flows and Movements." Contemporary Political Theory, 15, no 2, 160-181.

Spaargaren, Gert and van Vliet, Bas. 2000. "Lifestyles, Consumption and the Environment: The Ecological Modernisation of Domestic Consumption." In Ecological Modernisation around the World: Perspectives and Critical Debates, edited by Arthur P. Mol and David A. Sonnefield, pp. 50-76. Essex: Frank Cass.

WRAP 2012. Valuing our Clothes, Waste and Resources Action Programme (WRAP), Banbury, Oxfordshire. www.wrap.org.uk/clothing

\section{Websites}

Kapfunde, M. 2017. "Sustainable Brand Vigga, Green Superheroes Disrupting Global Fast Fashion in Kidswear?" 14 June. https://fashnerd.com/2017/06/vigga-brand -sustainable-kidswear-fashion/

Rent the Runway. 2020. https://www.renttherunway.com/

VIGGA - a circular subscription model for children's wear. 2014. https://www .littlescandinavian.com/2014/11/04/vigga-a-circular-subscription-model-for -childrens-wear/

\section{Interviews}

Liisa Jokinen, Vaatelainaamo, Fashion Libary, 2020. Interview by Kirsi Niinimäki 6 January 2020.

Soile-Maria Linnemäki, Vaatepuu-leasing company, 2020. Interview by Kirsi Niinimäki, Järvenpää, Finland 3 January 2020. 